\title{
Acute and critically ill peripartum cardiomyopathy and 'bridge to' therapeutic options: a single center experience with intra-aortic balloon pump, extra corporeal membrane oxygenation and continuous-flow left ventricular assist devices
}

\author{
Sofie Gevaert ${ }^{*}$, Yves Van Belleghem², Stefaan Bouchez ${ }^{3}$, Ingrid Herck ${ }^{4}$, Filip De Somer ${ }^{2}$, Yasmina De Block ${ }^{1,2}$,
} Fiona Tromp ${ }^{1}$, Els Vandecasteele ${ }^{1}$, Floor Martens ${ }^{4}$, Michel De Pauw ${ }^{1}$

\begin{abstract}
Introduction: Peripartum cardiomyopathy (PPCM) patients refractory to medical therapy and intra-aortic balloon pump (IABP) counterpulsation or in whom weaning from these therapies is impossible, are candidates for a left ventricular assist device (LVAD) as a bridge to recovery or transplant. Continuous-flow LVADs are smaller, have a better long-term durability and are associated with better outcomes. Extra corporeal membrane oxygenation $(E C M O)$ can be used as a temporary support in patients with refractory cardiogenic shock. The aim of this study was to evaluate the efficacy and safety of mechanical support in acute and critically ill PPCM patients.
\end{abstract}

Methods: This was a retrospective search of the patient database of the Ghent University hospital (2000 to 2010).

Results: Six PPCM-patients were treated with mechanical support. Three patients presented in the postpartum period and three patients at the end of pregnancy. All were treated with IABP, the duration of IABP support ranged from 1 to 13 days. An ECMO was inserted in one patient who presented with cardiogenic shock, multiple organ dysfunction syndrome and a stillborn baby. Two patients showed partial recovery and could be weaned off the IABP. Four patients were implanted with a continuous-flow LVAD (HeartMate $\|^{\circledR}$, Thoratec Inc.), including the ECMO-patient. Three LVAD patients were successfully transplanted 78, 126 and 360 days after LVAD implant; one patient is still on the transplant waiting list. We observed one peripheral thrombotic complication due to IABP and five early bleeding complications in three LVAD patients. One patient died suddenly two years after transplantation.

Conclusions: In PPCM with refractory heart failure IABP was safe and efficient as a bridge to recovery or as a bridge to LVAD. ECMO provided temporary support as a bridge to LVAD, while the newer continuous-flow LVADs offered a safe bridge to transplant.

\section{Introduction}

Peripartum cardiomyopathy (PPCM) is a rare disease that affects women in the last month of their pregnancy or in the early puerpium (up to five months after delivery); it is characterized by left ventricular systolic dysfunction and symptoms of heart failure without any

\footnotetext{
* Correspondence: sofie.gevaert@ugent.be

'Department of Cardiology, Heart Center, Ghent University Hospital, De Pintelaan 185, 9000 Ghent, Belgium

Full list of author information is available at the end of the article
}

identifiable cause of heart failure. The incidence varies from 1:15,000 to 1:1,300 deliveries in some African countries and 1:299 in Haiti and is thought to be lower in Europe [1,2]. The historically bad prognosis with mortality rates ranging from 4 to $80 \%$ has improved because of advances in heart failure treatment [3].

Although already described in the $19^{\text {th }}$ century the condition was only defined as Peripartum Cardiomyopathy in 1971 by Demakis et al., who also proposed diagnostic criteria that later were confirmed during the 
'Peripartum Cardiomyopathy: National Heart Lung and Blood Institute and Office of Rare Disease Workshop' in 2000 [4]. Several etiologies have been proposed comprising myocarditis, auto-immune mechanisms and pregnancy associated hormonal changes [5-7]. Recent data support the hypothesis that PPCM may develop as a result of complex interactions of pregnancy-associated factors against a susceptible genetic background $[8,9]$. The oxidative stress-cathepsin D-16 kDa prolactin hypothesis has been raised as a possible common pathway on which different etiologies that induce PPCM may merge. While newer therapies such as bromocriptine appear promising and will be tested in larger trials one must also concentrate on an optimal treatment strategy for the acute and critically ill PPCM patients, allowing to increase survival in this young patient population [10].

Heart transplantation is an accepted treatment option for patients with refractory heart failure due to PPCM, although a higher incidence of rejection has been reported in parous women, particularly in the first six months after transplantation [11,12]. Moreover, heart transplantation is limited by a lack of suitable donors. On the other hand there is a reasonable possibility of partial or complete recovery of left ventricular function, during the first year. The main predictors for recovery are an initial left ventricular end-diastolic dimension $<56 \mathrm{~mm}$ and an ejection fraction $>45 \%$ at two months [3]. As a consequence there is a need for appropriate temporary short- and long-term artificial support for the acute and critically ill patients. There are only a few reports on mechanical support devices as a bridge to recovery or transplantation in this setting. Data on the use of intra aortic balloon pump (IABP) and extra corporeal membrane oxygenation (ECMO) in PPCM are scarce [13-16]. There are a few reports on the use of pulsatile assist devices in this setting, most of them as a bridge to transplant and in a minority of cases as bridge to recovery [17-24].

Continuous-flow LVADs are a newer type of assist devices that have advantages over the older pulsatile devices: they are smaller, have a better long-term durability and their use is associated with improved survival and functional capacity $[25,26]$. There are no published series on the use of a continuous-flow device in patients with PPCM.

\section{Materials and methods}

A retrospective 10-year study (2000 to 2010) was conducted of our patient database (Department of Cardiology, Ghent University Hospital, Belgium) for patients with a need for mechanical support in the acute phase of PPCM. Mechanical support was defined as IABP, ECMO or LVAD. We received local Ethical Committee approval and informed consent from the patients or their relatives.

Diagnosis of PPCM was based upon development of symptoms of heart failure due to systolic dysfunction in the last month of pregnancy or within five months after delivery without any identifiable cause of heart failure or recognizable heart disease prior to the last month of pregnancy. Patients with hypertensive heart failure in the peripartum period were not included. Demographic, clinical, hemodynamic and echocardiographic data as well as data on serology were evaluated. Data on endomyocardial biopsies and coronary angiography were reviewed. The outcomes of the different treatment strategies as well as their complications were evaluated.

\section{Results}

Over a 10-year period six PPCM patients were treated with mechanical support for acute heart failure at our center (Table 1). All six patients were treated with an IABP and one patient was treated with ECMO. Four patients were implanted with a continuous-flow LVAD (HeartMate $\mathrm{II}^{\circledR}$, Thoratec Inc., Pleasanton, California, USA), three of them were transplanted and one patient is still on the transplant waiting list. The mean age at presentation was 34.7 years, the mean body surface area (BSA) was $1,76 \mathrm{~m}^{2}$. Five patients were Caucasian, one was native African. All patients but one were multiparous with the number of pregnancies ranging from two to four. Serology was examined for Coxsackie virus B15, Mycoplasma pneumoniae, toxoplasmosis, hepatitis B and C, HIV, Ebstein-Barr and adeno- and entero-virus in all patients. Active infection with Mycoplasma pneumoniae was found in two patients but active myocarditis was excluded by means of endomyocardial biopsy. Endomyocardial biopsies in two other patients, taken at the time of placement of the LVAD, were also negative for myocarditis.

\section{Presentation in the postpartum period}

Patient 1 was a 34-year-old patient (G4A0P4) who presented with acute pulmonary edema 16 days after delivery of a healthy son. She was initially treated with intravenous diuretics and vasodilators, but her condition only stabilized after insertion of an IABP. After initiation of conventional heart failure therapy with ACE-inhibitors, diuretics and low dose beta-blockers the patient was easily weaned off the IABP and discharged home four weeks after admission. She is still in follow-up and doing well under treatment with beta-blocking agents.

Patient 2 was a 35-year-old South African woman (G2A0P2) who developed progressive dyspnea from the fifth month postpartum. She came to the Emergency Room a few months later with a clinical picture of severe decompensated heart failure with lactate acidosis 
Table 1 Patient characteristics

\begin{tabular}{|c|c|c|c|c|c|c|}
\hline Patient & 1 & 2 & 3 & 4 & 5 & 6 \\
\hline Year & 2001 & 2008 & 2010 & 2007 & 2008 & 2009 \\
\hline Age (y) & 34 & 35 & 36 & 37 & 38 & 28 \\
\hline BSA $\left(m^{2}\right)$ & 1.90 & 1.88 & 1.58 & 1.83 & 1.60 & 1.79 \\
\hline Race & C & A & C & C & C & $C$ \\
\hline Obstetrical Hx & G4AOP4 & G2AOP2 & G4AOP4 & G1A0P0 & G2AOP1 & G3A1P1 \\
\hline Symptom onset & $3 W P P$ & $5 \mathrm{mPP}$ & $5 \mathrm{mPP}$ & $38 w P r$ & $35 w P r$ & $38 w P r$ \\
\hline Diagnosis & $3 w P P$ & $10 \mathrm{mPP}$ & $18 \mathrm{mPP}$ & $38 \mathrm{WPr}$ & $36 w P r$ & $38 w P r$ \\
\hline Clinical picture & APE & ADHF & ADHF & $\mathrm{ADHF}$ & $\mathrm{ADHF}$ & CS \\
\hline LVEDD (mm) & 55 & 62 & 79 & 53 & 61 & 68 \\
\hline Serology & Negative & Mycoplasma IgM & Negative & Negative & Negative & Myocplasma IgM \\
\hline Coronary angio & Normal & - & Normal & - & Normal & - \\
\hline Biopsy & - & Negative & Negative & - & Negative & Negative \\
\hline IABP (d) & 7 & 13 & 5 & 4 & 6 & 1 \\
\hline ECMO (d) & - & - & - & - & - & 7 \\
\hline LVAD (d) & - & 126 & Since 26/04/2010 & - & 360 & 78 \\
\hline Complications & - & $\begin{array}{l}\text { Perop. rupture aorta } \\
\text { Tamponade } 2 x \\
\text { Pocket Infection }\end{array}$ & $\begin{array}{l}\text { Rectus hematoma } \\
\text { Occlusion AFC }\end{array}$ & - & - & Bleeding anast. aorta \\
\hline Outcome & Recovery & Tx, SD 535 days postTx & Alive, on Tx list & Recovery & $T x$ & Tx \\
\hline
\end{tabular}

and liver failure. After initiation of inotropic therapy and IABP insertion her condition stabilized with complete resolution of the lactate acidosis and liver function. Despite initiation of proper heart failure therapy, weaning off the IABP was not possible and the implantation of a LVAD was decided. The implantation was complicated by a rupture and large hematoma of the descending aorta for which an endoprosthesis was inserted. During the early postoperative phase 2 revisions were necessary because of pericardial tamponade. Long-term antibiotic therapy was initiated because of infection of the pocket. After a long postoperative period the patient could be mobilized and discharged home 67 days after placement of the LVAD. No recovery in left ventricular function was noted during follow-up. A total of 126 days after implantation of the LVAD she was successfully transplanted and did well. Unfortunately she died suddenly two years later, she developed electromechanical dissociation during hospitalization for heart failure due to mild rejection, prolonged resuscitation was unsuccessful. An autopsy was not performed.

Patient 3, a 36-year-old mother of four children, presented very late in the postpartum period (18 months postpartum), she developed progressive symptoms of heart failure during the first months after her last delivery. She presented with cachexia and decompensated heart failure. The left ventricular end-diastolic diameter was $79 \mathrm{~mm}$ at presentation. After minor decongestion with diuretics, low dose dopamine was started and an
IABP was inserted because of refractory hypotension and low output failure. Five days later an LVAD was implanted electively because of lack of left ventricular recovery and the impossibility to wean the patient off the IABP and dopamine. The postoperative course was complicated by a spontaneous rectus hematoma at the $11^{\text {th }}$ postoperative day (supratherapeutic prothrombin time) and a thrombotic occlusion of the right common femoral artery. The arterial occlusion was a consequence of the IABP and a thrombectomy was performed at Day 35 post LVAD with good clinical resolution afterwards. During ambulatory follow-up, left ventricular end diastolic diameter decreased from 79 to $72 \mathrm{~mm}$ without recovery of left ventricular function.

\section{Presentation late in pregnancy}

Two patients presented with acute decompensated heart failure and were in New York Heart Association class III. An IABP was inserted in both patients prior to caesarian section.

Patient 4, a 37-year-old nullipara could be weaned off the IABP four days later and is still under treatment with conventional heart failure therapy and is doing well.

Patient 5, a 38-year-old woman (G2A0P1) could be weaned off the IABP after six days but remained symptomatic the following weeks with severe hypotension necessitating a continuous dopamine infusion. She was treated with bromocriptine but remained inotrope-dependent. 
She was implanted with a LVAD 21 days after removal of the IABP. There were no complications. Follow-up echocardiography showed some recovery of left ventricular function but the right ventricular function remained moderate; a trial to remove the LVAD was not attempted. She was successfully transplanted almost one year after LVAD placement and is still doing well.

The sixth patient, a 28-year-old G3A1P1 developed rapidly progressive dyspnea at the end of pregnancy. Heart failure was initially not recognized and delivery was induced with prostaglandins. Afterward she rapidly progressed to cardiogenic shock. She was referred to our center. During transport a continuous infusion with adrenaline was initiated because of severe shock. Upon arrival the patient was immediately intubated, meanwhile an IABP was percutaneously inserted. A stillborn baby was delivered by caesarean section. The patient remained in shock with severe lactate acidosis and multiple organ dysfunction syndrome despite treatment with dobutamine, levosimendan and high doses of noradrenaline. Her condition worsened rapidly, she was not stable enough for implantation of a LVAD. An ECMO was percutaneously inserted at the bedside without complications. The system comprised a Medos Hilite 7000 LT oxygenator (Medos Medizintechnik AG, Stolberg, Germany) and a Sorin revolution centrifugal pump (Sorin Group, Arvado, Colorado, USA) (18 Fr arterial line: femoral approach, $18 \mathrm{Fr}$ venous line: jugular approach). The following days we noted respiratory and metabolic improvement. Because of the absence of left ventricular recovery a LVAD was implanted after seven days of ECMO. There was a revision at Day 1 because of bleeding at the anastomosis of the aortic cannula. During the postoperative course she was treated for ventilator associated pneumonia with complete recovery. Sildenafil treatment for moderate right ventricular function and pulmonary hypertension was initiated at the fourth day post-LVAD implantation until transplant. She was discharged home 37 days after initial admission and was successfully transplanted 78 days after LVAD implant and is doing well up till now.

\section{Discussion}

We describe six well-documented cases of severe PPCM that presented with acute heart failure requiring mechanical support. The diagnosis was based upon development of symptoms of heart failure in the last month of pregnancy or during the first five months after delivery without arguments for pre-existing structural heart disease. In each patient an extensive work-up was performed to exclude other causes of heart failure. Two patients had arguments for active Mycoplasma pneumoniae infection, but myocarditis was excluded by means of endomyocardial biopsies.
We describe short- and/or long-term mechanical support when intensive medical therapy fails to stabilize a PPCM patient with severe heart failure. Mechanical short-term support can be provided percutaneous with IABP or ECMO. An IABP can easily be placed at the bedside and has little side effects in this young patient population. There are no randomized data on the use of IABP in non-ischemic refractory heart failure and European guidelines recommend insertion of an IABP when inotropes fail to restore the blood pressure and signs of hypoperfusion persist [27]. In our series the use of IABP up to 13 days was complicated by one thrombotic occlusion of the common right femoral artery, which was corrected uneventfully after thrombectomy. All patients treated with IABP were anticoagulated with unfractionated heparin (UFH) aiming at an activated partial thromboplastin time (aPTT) of 65 to 85 seconds. Weaning from the IABP is usually attempted over one to three days by gradually decreasing the $1: 1$ support to a 1:2 and a 1:3 support. If a 1:3 support is well tolerated for at least four hours, the IABP is removed. When weaning off the IABP is not possible, the IABP is removed at the time of implantation of the ECMO or the LVAD.

There is a current trend to use short-term support with ECMO in refractory cardiogenic shock but data from large randomized trials are lacking. ECMO is considered an emergency rescue therapy for patients with refractory cardiogenic shock; their condition is so unstable that they are not eligible for immediate LVAD implantation. The ECMO can be inserted at the bedside; it is relatively cheap (as compared to the implantable LVAD) and gives the treating physicians some time to wait for recovery or a more stable condition. However, close monitoring of the coagulation parameters is needed and it is, therefore, labour-intensive. Patients on ECMO are treated with UFH in order to obtain an activated clotting time (ACT) of 170 to 200 seconds. Antithrombin III (ATIII) levels are analyzed daily, ATIII concentrate is given if the ATIII activity drops below $70 \%$. A visco-elastic coagulation measurement is checked twice daily or whenever bleeding occurs. Patients on arterio-venous ECMO are ventilated with conventional settings, with a $\mathrm{FiO}_{2}$ to achieve an acceptable $\mathrm{PaO}_{2}$ (at least $60 \mathrm{mmHG}$ ). Inotropic support is reduced and stopped but milrinone is often continued for its dilator properties and positive effects on microcirculation. Fluid management is aimed at preserving renal function and ensuring a stable circulation. As ECMO flow depends on right atrial filling, this is monitored by means of echocardiography. During a weaning attempt each partial decrease in ECMO flow should be compensated by an increase in stroke volume without excessive increase in inotropic support. There are three 


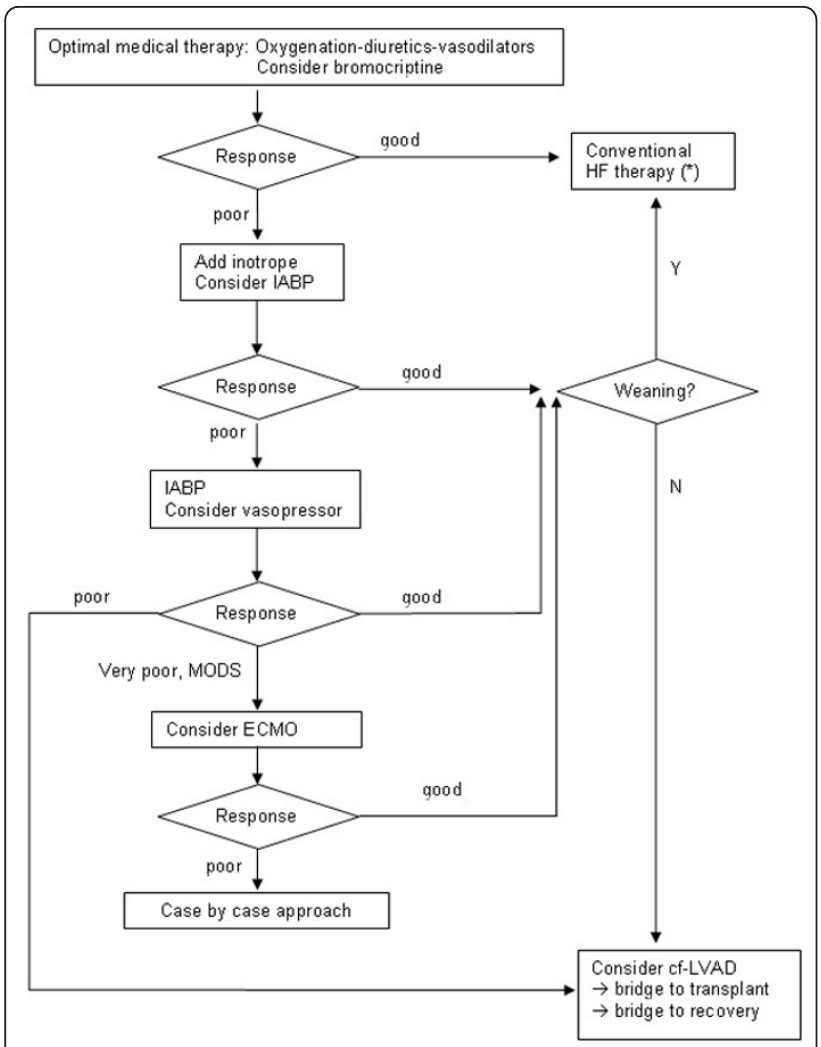

Figure 1 Algorithm for the treatment of acute and critically ill PPCM. PPCM, peripartum cardiomyopathy; HF, Heart Failure; $\left(\left(^{*}\right)=\right.$ Avoid ACE-inhibitors, angiotensin II receptor blockers and aldosterone antagonists during pregnancy; Cf-LVAD, continuous-flow left ventricular device; ECMO, extracorporeal membrane oxygenation; IABP, intra aortic balloon pump; MODS, multiple organ dysfunction syndrome.

case reports on ECMO in PPCM where ECMO served as a safe bridge to recovery [14-16]. In our series ECMO was used in one patient because of refractory cardiogenic shock and multiple organ dysfunction syndrome one-day post caesarean section. ECMO allowed hemodynamic and metabolic stabilization. In contrast to the above mentioned case reports we saw no recovery of left ventricular function and in our patient ECMO served as a bridge to LVAD.

LVADs offer a more long-term support. In a recent position statement Sliwa et al. promote the use of a mechanical assist device in PPCM in case of refractory heart failure despite optimal medical therapy [28]. The continuous-flow HeartMate II was introduced in 2004 and has shown improvement in survival, reduction in adverse events and improved functional capacity [25]. This axial flow pump draws the blood on a continuous basis from the left ventricle via an apical drainage cannula and propels it back into the aorta by a rotary pump in a nonphasic flow pattern. Its smaller size makes it suitable for patients with a low BSA, which is frequently the case in this young female population. After implantation of the LVAD NO-ventilation is routinely applied in our center to support the right ventricle, inotropic support is gradually decreased and replaced by oral heart failure therapy. Echocardiography is used to assess left ventricular filling, a neutral interventricular septum position indicates adequate left ventricular filling. Bleeding complications in the immediate postoperative phase still pose a problem but recent data on the HeartMate II device support a less aggressive anticoagulation protocol $[18,22]$. More recently late bleeding complications up to 44.3\% have been observed in continuous-flow LVAD patients, possibly due to an acquired von Willebrand Syndrome [29]. In our center the antithrombotic regimen is started as soon as drain output reaches levels of $50 \mathrm{ml} /$ $\mathrm{h}$ or less. It comprises Aspirin $100 \mathrm{mg}$ and Enoxaparin 40 $\mathrm{mg}$ once daily $(20 \mathrm{mg}$ in case of GFR $<30 \mathrm{ml} / \mathrm{minte}, 60$ $\mathrm{mg}$ in case of body weight $>90 \mathrm{~kg}$ ). Acenocoumarol (target INR 1.5 to 2 ) is started as soon as a more stable hemodynamic condition is reached and in the absence of bleeding. Bleeding complications were observed in three patients during the early postoperative phase, with need for revision in two patients. We observed no late bleeding complications. Infection of the pocket with the need for long-term antibiotic treatment occurred in one patient. There were no thrombotic complications related to the LVAD, despite the fact that PPCM is a pro-thrombotic condition. Right heart failure, defined as the postoperative need for temporary right ventricular mechanical or inotropic support for more than 14 days following implantation, was not noted although one patient was treated until transplantation with a low dose Sildenafil. Neurological complications did not occur in this small series. Sufficient recovery of left ventricular function to allow LVAD explantation is rare but has been described in PPCM patients treated with pulsatile devices, we found no data on explantation of continuous-flow devices in PPCM patients. In our series we saw a decrease in left ventricular end-diastolic diameter and some improvement in left ventricular function, but the right ventricular function remained moderate. In our opinion the decrease in left ventricular end diastolic diameter (LVEDD) and improvement in left ventricular function can be attributed to the unloading of the left ventricle.

These six patients presented over a wide time range between 2001 and 2010 with a trend towards an increasing incidence over the last three years at our center, this stresses the need for a national and international registry for this pathology. One could argue that the therapy has become more invasive over the years; the first two patients being managed with IABP alone. However, the more invasive therapy (ECMO, LVAD) in the patients who presented later is attributable to the more severe 
condition of these patients with the inability to wean the patients off IABP and/or intravenous inotropes.

Despite the fact that bromocriptine appears promising as a novel disease-specific treatment, we initiated it briefly in one patient (patient 5) and stopped it after implantation of the LVAD. Currently it is not clear whether the results of the proof of concept study by Sliwa et al., where bromocriptine was added to standard heart failure therapy (ACE-inhibitors, aldactone, betablockers and diuretics), can be extrapolated to this patient population dependent of IV inotropes and/or mechanical support. We hope that future trials will address this question.

\section{Conclusions}

In acute and critically ill PPCM patient's, mechanical support with IABP, even prior to delivery, is safe and feasible and serves as a bridge to partial recovery or as a bridge to LVAD. ECMO can serve as a bridge to LVAD, in case of refractory cardiogenic shock despite IABP and full inotropic support. The newer continuous-flow assist devices are a safe bridge to transplant for PPCM patients who cannot be weaned off intravenous inotropic support or mechanical support with IABP or ECMO. The role of bromocriptine treatment in these patients needs to be explored in future trials. Based on the literature and our experience we propose an algorithm for the treatment of acute and critically PPCM (Figure 1).

\section{Key messages}

- Acute and critically ill PPCM patients, refractory to medical therapy, should be treated with mechanical support.

- IABP support is feasible and safe in the pre- and postpartum period as a bridge to recovery or as a bridge to assist device.

- In patients with refractory cardiogenic shock and Multiple Organ Dysfunction Syndrome despite IABP, ECMO should be considered as a temporary 'emergency rescue' support (bridge to recovery or bridge to LVAD).

- Continuous-flow left ventricular assist devices are safe as a bridge to transplant in this young patient population.

- Bromocriptine, a novel disease-specific treatment, can be considered in these patients.

\footnotetext{
Abbreviations

ACT: activated clotting time; aPTT: activated partial thromboplastin time; ATIII: antithrombin III; ECMO: extra corporeal membrane oxygenation; IABP: intra aortic balloon pump; LVAD: left ventricular assist device; LVEDD: left ventricular end diastolic diameter; PPCM: peripartum cardiomyopathy; UFH: unfractionated heparin.
}

\section{Acknowledgements}

We wish to thank Mr Marc De Buyzere for his assistance during the writing process and Mr Dries Gaerdelen and Mrs Krista Van Vlaenderen for technical assistance.

\section{Author details}

${ }^{1}$ Department of Cardiology, Heart Center, Ghent University Hospital, De Pintelaan 185, 9000 Ghent, Belgium. ${ }^{2}$ Department of Cardiac Surgery, Heart Center, Ghent University Hospital, De Pintelaan 185, 9000 Ghent, Belgium. ${ }^{3}$ Department of Anesthesiology, Heart Center, Ghent University Hospital, De Pintelaan 185, 9000 Ghent, Belgium. ${ }^{4}$ Department of Intensive Care, Heart Center, Ghent University Hospital, De Pintelaan 185, 9000 Ghent, Belgium.

\section{Authors' contributions}

The idea for the article came from SG and MDP. SG, MDP, EVDC, FT, FM and $1 \mathrm{H}$ collected data and prepared the article. YVB, SB and FDS critically reviewed the paper. SG and MDP finalized the text. All authors read and approved the manuscript.

\section{Competing interests}

The authors declare that they have no competing interests.

Received: 6 December 2010 Revised: 1 February 2011

Accepted: 10 March 2011 Published: 10 March 2011

\section{References}

1. Abboud J, Murad Y, Chen-Scarabelli C, Saravolatz L, Scarabelli TM: Peripartum cardiomyopathy: a comprehensive review. Int J Cardio/ 2007, 118:295-303

2. Ferriere M, Sacrez A, Bouhour JB, Cassagnes J, Geslin P, Dubourg O, Komajda M, Degeorges M: [Cardiomyopathy in the peripartum period: current aspects. A multicenter study. 11 cases]. Arch Mal Coeur Vaiss 1990, 83:1563-1569.

3. Amos AM, Jaber WA, Russell SD: Improved outcomes in peripartum cardiomyopathy with contemporary. Am Heart J 2006, 152:509-513.

4. Demakis JG, Rahimtoola SH: Peripartum cardiomyopathy. Circulation 1971, 44:964-968.

5. Midei MG, DeMent SH, Feldman AM, Hutchins GM, Baughman KL: Peripartum myocarditis and cardiomyopathy. Circulation 1990, 81:922-928.

6. Sliwa K, Skudicky D, Bergemann A, Candy G, Puren A, Sareli P: Peripartum cardiomyopathy: analysis of clinical outcome, left ventricular function, plasma levels of cytokines and Fas/APO-1. J Am Coll Cardiol 2000, 35:701-705.

7. Hilfiker-Kleiner D, Kaminski K, Podewski E, Bonda T, Schaefer A, Sliwa K, Forster O, Quint A, Landmesser U, Doerries C, Luchtefeld M, Poli V, Schneider MD, Balligand JL, Desjardins F, Ansari A, Struman I, Nguyen NQ, Zschemisch NH, Klein G, Heusch G, Schulz R, Hilfiker A, Drexler H: A cathepsin D-cleaved $16 \mathrm{kDa}$ form of prolactin mediates postpartum cardiomyopathy. Cell 2007, 128:589-600.

8. van Spaendonck-Zwarts KY, van Tintelen JP, van Veldhuisen DJ, van der Werf R, Jongbloed JD, Paulus WJ, Dooijes D, van den Berg MP: Peripartum cardiomyopathy as a part of familial dilated cardiomyopathy. Circulation 2010, 121:2169-2175.

9. Morales A, Painter T, Li R, Siegfried JD, Li D, Norton N, Hershberger RE: Rare variant mutations in pregnancy-associated or peripartum cardiomyopathy. Circulation 2010, 121:2176-2182.

10. Sliwa K, Blauwet L, Tibazarwa K, Libhaber E, Smedema JP, Becker A, McMurray J, Yamac H, Labidi S, Struman I, Hilfiker-Kleiner D: Evaluation of bromocriptine in the treatment of acute severe peripartum cardiomyopathy: a proof-of-concept pilot study. Circulation 2010, 121:1465-1473.

11. Keogh A, Macdonald P, Spratt P, Marshman D, Larbalestier R, Kaan A: Outcome in peripartum cardiomyopathy after heart transplantation. J Heart Lung Transplant 1994, 13:202-207.

12. Johnson MR, Naftel DC, Hobbs RE, Kobashigawa JA, Pitts DE, Levine TB, Tolman D, Bhat G, Kirklin JK, Bourge RC: The incremental risk of female sex in heart transplantation: a multiinstitutional study of peripartum cardiomyopathy and pregnancy. Cardiac Transplant Research Database Group. J Heart Lung Transplant 1997, 16:801-812.

13. Brantigan CO, Grow JB Sr, Schoonmaker FW: Extended use of intra-aortic balloon pumping in peripartum cardiomyopathy. Ann Surg 1976, 183:1-4. 
14. Yang HS, Hong YS, Rim SJ, Yu SH: Extracorporeal membrane oxygenation in a patient with peripartum cardiomyopathy. Ann Thorac Surg 2007, 84:262-264.

15. Smith IJ, Gillham MJ: Fulminant peripartum cardiomyopathy rescue with extracorporeal membranous oxygenation. Int J Obstet Anesth 2009, 18:186-188.

16. Palanzo DA, Baer LD, El-Banayosy A, Stephenson E, Mulvey S, McCoach RM, Wise RK, Woitas KR, Pae WE: Successful treatment of peripartum cardiomyopathy with extracorporeal membrane oxygenation. Perfusion 2009, 24:75-79.

17. Hovsepian PG, Ganzel B, Sohi GS, Kupersmith J, Gray L Jr: Peripartum cardiomyopathy treated with a left ventricular assist device as a bridge to cardiac transplantation. South Med J 1989, 82:527-528.

18. Resano FG, Goldstein SA, Boyce SW: Thromboembolic complications in a peripartum cardiomyopathy patient supported with the Abiomed BVS5000 ventricular assist device. ASAIO J 1996, 42:240-241

19. Lewis R, Mabie WC, Burlew B, Sibai BM: Biventricular assist device as a bridge to cardiac transplantation in the treatment of peripartum cardiomyopathy. South Med J 1997, 90:955-958.

20. Tandler R, Schmid C, Weyand M, Scheld HH: Novacor LVAD bridge to transplantation in peripartum cardiomyopathy. Eur I Cardiothorac Surg 1997, 11:394-396.

21. Colombo J, Lawal AH, Bhandari A, Hawkins JL, Atlee JL: Case 1-2002-a patient with severe peripartum cardiomyopathy and persistent ventricular fibrillation supported by a biventricular assist device. J Cardiothorac Vasc Anesth 2002, 16:107-113.

22. Monta O, Matsumiya G, Fukushima N, Miyamoto Y, Sawa Y, Koseki M, Nakamichi I, Matsuda H: Mechanical ventricular assist system required for sustained severe cardiac dysfunction secondary to peripartum cardiomyopathy. Circ J 2005, 69:362-364.

23. Oosterom L, de Jonge N, Kirkels J, Klopping C, Lahpor J: Left ventricular assist device as a bridge to recovery in a young woman admitted with peripartum cardiomyopathy. Neth Heart J 2008, 16:426-428.

24. Zimmerman H, Bose R, Smith R, Copeland JG: Treatment of peripartum cardiomyopathy with mechanical assist devices and cardiac transplantation. Ann Thorac Surg 2010, 89:1211-1217.

25. Miller LW, Pagani FD, Russell SD, John R, Boyle AJ, Aaronson KD, Conte JV, Naka Y, Mancini D, Delgado RM, MacGillivray TE, Farrar DJ, Frazier OH: Use of a continuous-flow device in patients awaiting heart transplantation. $N$ Engl IJ Med 2007, 357:885-896.

26. Russell SD, Rogers JG, Milano CA, Dyke DB, Pagani FD, Aranda JM, Klodell CT, Boyle AJ, John R, Chen L, Massey HT, Farrar DJ, Conte JV: Renal and hepatic function improve in advanced heart failure patients during continuous-flow support with the HeartMate II left ventricular assist device. Circulation 2009, 120:2352-2357.

27. Dickstein K, Cohen-Solal A, Filippatos G, McMurray JJ, Ponikowski P, PooleWilson PA, Stromberg A, van Veldhuisen DJ, Atar D, Hoes AW, Keren A, Mebazaa A, Nieminen M, Priori SG, Swedberg K, Vahanian A, Camm J, De Caterina R, Dean V, Dickstein K, Filippatos G, Funck-Brentano C, Hellemans I, Kristensen SD, McGregor K, Sechtem U, Silber S, Tendera M, Widimsky P, Zamorano JL: ESC Guidelines for the diagnosis and treatment of acute and chronic heart failure 2008: the Task Force for the Diagnosis and Treatment of Acute and Chronic Heart Failure 2008 of the European Society of Cardiology. Developed in collaboration with the Heart Failure Association of the ESC (HFA) and endorsed by the European Society of Intensive Care Medicine (ESICM). Eur Heart J 2008, 29:2388-2442.

28. Sliwa K, Hilfiker-Kleiner D, Petrie MC, Mebazaa A, Pieske B, Buchmann E, Regitz-Zagrosek V, Schaufelberger M, Tavazzi L, van Veldhuisen DJ, Watkins H, Shah AJ, Seferovic PM, Elkayam U, Pankuweit S, Papp Z, Mouquet F, McMurray Jj: Current state of knowledge on aetiology, diagnosis, management, and therapy of peripartum cardiomyopathy: a position statement from the Heart Failure Association of the European Society of Cardiology Working Group on peripartum cardiomyopathy. Eur J Heart Fail 2010, 12:767-778.

29. Uriel N, Pak SW, Jorde UP, Jude B, Susen S, Vincentelli A, Ennezat PV, Cappleman S, Naka Y, Mancini D: Acquired von Willebrand syndrome after continuous-flow mechanical device support contributes to a high prevalence of bleeding during long-term support and the time of transplantation. J Am Coll Cardiol 2010, 56:1207-1213.

\section{doi:10.1186/cc10098}

Cite this article as: Gevaert et al: Acute and critically ill peripartum cardiomyopathy and 'bridge to' therapeutic options: a single center experience with intra-aortic balloon pump, extra corporeal membrane oxygenation and continuous-flow left ventricular assist devices. Critical Care 2011 15:R93.

\section{Submit your next manuscript to BioMed Central and take full advantage of:}

- Convenient online submission

- Thorough peer review

- No space constraints or color figure charges

- Immediate publication on acceptance

- Inclusion in PubMed, CAS, Scopus and Google Scholar

- Research which is freely available for redistribution 